\title{
Book Review \\ Essentials of Modern Management
}

UDC: $005.13(075.8)(049.32)$

DOI: 10.7595/management.fon.2015.0006

Slavica Mitrović, Boban Melović, The Principles of Modern Management, Faculty of Technical Sciences, Novi Sad, 2013, pp.535. ISBN: 978-86-7892-487-3

Textbooks serve as an important and powerful educational and instructional aid on condition that they are content, methodologicaly and graphically well devised. They facilitate the cognition process offering contents of the greatest value for a given course or a given scientific discipline, in a well organized and systematic manner. Textbooks help incorporate new knowledge into an individual structure of knowledge; they serve as support in the development of new intellectual operations, they enhance autonomy in thinking. According to Dijana Plut (Textbook as cultural-supportive system (in Serbian), ZUNS, Beograd, 2003), textbooks help support practical activities following the emergence of new psychical structures or are even a precondition for them, binding together different systems, different functions and symbolic domains. Finally, this type of literature affects modelling of behaviour, motivation for learning, and especially forming a value system of an individual and even of the entire generations of students.

At the time when university lecturers are burdened with the "SSCI list syndrome", as wittily defined by Chuing Prudence Chou (The SSCI Syndrome in Higher Education, 2014), there is a decreasing number of those willing to devote themselves to a highly demanding task of creating a textbook. This is so for a number of reasons. The first, pragmatic reason is that, in veiw of evaluation of scientific contribution, the textbook is not valued as a significant scientific reference; actually, it is not valuated at all. Secondly, when announcing the contents and outcomes of their subject and their exam requirements, the lecturers often inform their students on abundant available literature of any kinds, whereby they confuse students and put themselves into an ambiguous position. Thirdly, increasingly frequent changes in curricula make teachers unable to and discourage them to devote themselves to a thorough and long-term study of one scientific discilpine, namely, to immerse themselves in defining the subject and method of a given discipline, define the necessary notions and concepts, explain their meaning, illustrate all these with examples, formulate statements - all these in a manuscript structured as a textbook.

It is for this reason that the recently published textbook, The Principles of Modern Management, by two young authors, assisstant professors Slavica Mitrović and Boban Melović, both committed to the study of principles of modern organizational management, deserves our attention. The book reviewers, Prof. Dr. Ilija Ćosić and Prof. Dr. Gordana Kokeza almost unanimously state that this textbook is based on the modern theoretical and practical contributions to management in any types of organizations.

Following the basic principles of a good textbook - that it is a functional educational tool, that it offers a valuable selection of contents in a systematic manner, that it ensures a deep insight into the subject matter in a manner attractive to target groups it is meant for - the authors structured the text into thirteen easyto-survey chapters, i.e., theme areas. Between the graphically attractive covers of the book, in 535 pages, the authors arranged seemingly heterogeneous topics into a content-rich and consistent text whose problem matter in general is the principles of modern organizational management, treating this complex phenomenon primarily from the point of view of engineering management. 
The authors are very cautios in defining a multi-layer concept of management, offering numerous and nuanced interpretations, finding a common denominator of this concept in its three key words, namely: process, achieving organizational goals and managing resources - human and financial, raw materials and capital. They conclude with a more than acceptable diagnosis that a common constant of management is contained in improving business on the basis of goal achievement through optimal business decisions and through employees' purposive work. Evidently sincerely committed to this research area, Mitrović and Belović define management as the oldest, the most important, the most numerous, the most complex, the most effortful, the most risky and the most controversial profession. The authors point out that management engineer is today one of the most popular professions since, according to research (APESMA), about 35\% engineers see themselves as holders of the management functions.

Providing a neat survey of management schools, the authors tackle the issue of interdisciplinary nature of the management science through, on the one hand, the relationship of management with the natural and social sciences, through general, specific and individual sciences, and, on the other hand, through the interdisciplinary character of management regarding certain academic and, in the managerial practice, developed areas. They continue to branch the interdisciplinary identity of management into strategic, operations, entrepreneurial and financial management, management in services, banking, tourism, accomodation industry, commerce, health care, transportation, sports, public sector, education, culture, media, agriculture. The authors pay special attention to engineering management, pointing out that the management engineers, as a rule, do not deal with technical affairs; they rather act via human resources, using varied decision-making methods, such as Kepner-Tragoe method, Monte Carlo method, etc.

A somewhat closer attention, according to the scope and various aspects of analysis, is paid to knowledge, skills and types of managers, especially to the managers in the domestic business practice. The authors differ between "aroused" and "dormant" managers, usurper-managers or quasi-managers and "self-made" managers, stressing that management in the Serbian business practice is understood rather as a function, not a profession, and illustrate it by the syndrome of political (clientelistic - authors' remark) management. Hence, three basic groups of managerial knowledge and skills are necessary in order that business success should be achieved: technical skills and knowledge, knowledge and skills of handling people and conceptual knowledge and skills in the sense of (onthological and epistemological - authors' remark) skills and capabilities of abstract thinking, diagnosing and forecasting. These are also the preconditions of efficiency and effectiveness of managerial activities given that, in case these managerial performances are absent, it is possible that an efficient business system fails to produce effective outcomes and vice-versa.

Listing the modern approaches to management that enable managers to successfully respond to the challenges of modern business, the authors describe the concept of re-engineering, Customer Relationship Management (CRM), Total Quality Management (TQM), six sigma approach ("magic of quality"), the LEAN concept, green management, knowledge management concepts, learning organization, Balanced Scorecard (BSC) and brand management. It is in this context that they describe the functions of management and managerial activities and present modern organizational models in detail.

The authors devoted more that fifty pages to an important issue of leadership where they explain the importance of leadership from a number of aspects, primarily from that of power, namely, an individual's ability to affect the behaviour and the changes in the behaviour of other individuals or groups, through the dimensions of authority, influence and responsibility. The authors discuss the leadership styles, the importance of personal traits for an effective leadership, as well as modern approaches to ledership, such as: charismatic, transformational, team, emotional, ethical, online, intercultural, heroic and effective.

One issue that Mitrović and Melović also included in their book is the issue of corporate social responsibility in the sense of the consequences of organizational impact upon the society, stressing the fundamental principles of responsibility, namely: honest and equal behaviour towards employees, ethical and honest business doing, respect for the basic human rights, responsible conduct towards environment and the society in general. Organizations develop different strategies of social responsibility, such as 
defensive, investment and commercial strategy, externally or internally oriented socially responsible business activities and socially responsible business doing as an organizational business style.

Towards the end of this voluminous manuscript the authors offer the examples of management in ten organizations, among which are manufacturing organizations, media conglomerates, health care, telecommunication and pharmaceutical organizations. The authors conclude the book with ten tests in which they test general managerial skills, time management, decision-making style and method, motivation, emotional intelligence, control, and finally, the extent to which the reader mastered the acquired knowledge.

It is our suggestion that an index of concepts and authors should be helpful in better understanding the contents. Nevertheless, we hope that Slavica Mitrović and Boban Melović's book, The Principles of Modern Management, will be widely read and studied, not only among the beginners in this field of study but also among the advanced students and experts whose professional interests are the principles of modern organizational management. Together with a significant theoretical dimension it has, this book is also, in all its aspects, composed as a modern pedagogical reading material - for learning and for study.

Receieved: December 2014 Accepted: February 2015. 